\title{
Uma sequência didática para o ensino de polígonos: o uso de materiais manipuláveis no quinto ano do ensino fundamental
}

Cileide Teixeira da Silva Polli

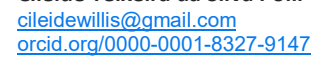
Faculdade Pitágoras, Londrina, Paraná, Brasil Helenara Regina Sampaio Figueiredo helenara@kroton.com.br orcid.org/0000-0001-7974-0818 Faculdade Pitágoras, Londrina, Paraná, Brasil

\section{RESUMO}

O presente artigo resultou de um recorte de uma pesquisa de mestrado acerca do desenvolvimento do pensamento geométrico do aluno. O estudo teve foco no estudo dos polígonos com o objetivo de investigar as possíveis aplicações de materiais manipuláveis no ensino de Geometria no 5o ano do Ensino Fundamental. A metodologia adotada neste estudo foi de natureza qualitativa, no qual apresentamos os resultados de um dos momentos da aplicação de uma sequência didática sobre polígonos. A fundamentação teórica se baseia em autores como Lorenzato (1995), que defende a presença da Geometria no ensino de Matemática, a partir do argumento de que este conhecimento deve ser construído desde a Educação Infantil, visto que auxilia na solução dos problemas do cotidiano, os quais, muitas vezes, são geometrizados. Os resultados obtidos apontam para a possibilidade de que os materiais manipuláveis possam potencializar a construção do saber geométrico em alunos do 5 o ano do Ensino Fundamental. Ademais, constatou-se que o uso de materiais manipuláveis se apresenta como uma possibilidade de imprimir maior significado à construção dos conceitos geométricos, na medida em que permitem aos alunos manipular, comparar, recortar, pesquisar, observar e construir conceitos. Foram ainda encontradas evidências de que esse tipo de material facilita a observação e a análise por favorecer o desenvolvimento do raciocínio lógico e crítico, essenciais para a construção dos diferentes saberes matemáticos.

PALAVRAS-CHAVE: Ensino de Matemática. Geometria. Materiais manipuláveis. 


\section{INTRODUÇÃO}

O ensino de Matemática, embora tenha reconhecida importância no processo de compreensão de mundo, nem sempre consegue contornar dificuldades que surgem em sua prática, sejam elas no domínio do conteúdo pelos alunos ou mesmo na metodologia adotada pelo professor.

Quanto ao domínio do conteúdo, é fato incontestável que ele se reveste de maior significado quando o estudante se envolve em atividades cuja prioridade está em promover seu protagonismo no processo de aquisições dos conceitos necessários à construção dos saberes matemáticos (LORENZATO, 2006). O uso de materiais manipuláveis permite ao aluno construir seu conhecimento por despertar a curiosidade e incentivar a criatividade, tornando-o apto a assumir o papel de protagonista de sua própria aprendizagem.

No que diz respeito à metodologia de ensino, os materiais didáticos manipuláveis constituem um importante recurso didático a serviço do professor em sala de aula. Podem tornar as aulas de Matemática mais dinâmicas e compreensíveis, uma vez que aproximam a teoria matemática da sua constatação na prática, por meio da ação manipulativa.

A proposição deste trabalho se ampara em autores como Lorenzato (1995), que defendem a presença da Geometria no ensino de Matemática, afirmando que esse conhecimento deve ser construído desde a Educação Infantil, visto que auxilia na solução dos problemas do cotidiano, os quais, muitas vezes, são geometrizados.

Apoia-se, ainda, em Passos (2000), que aprofunda esse argumento, pois defende a ideia de que a Geometria representa um campo de conhecimento de extrema relevância para a inter-relação do homem com o espaço em que vive, assumindo a posição de parte mais intuitiva e concreta da Matemática, articulada à realidade, sendo, assim, vital para o processo de formação dos alunos.

Outra referência teórica importante é Nacarato e Passos (2003), cujo trabalho levanta a possibilidade de o trabalho com a Geometria nos anos iniciais poder desencadear diferentes raciocínios geométricos dos alunos, os quais podem se transformar em importantes elementos na construção do pensamento geométrico. No entanto, as intervenções docentes requerem um saber disciplinar pedagógico e curricular da Geometria que nem sempre se encontra disponível nos professores, dada sua formação inicial generalizada.

Esses posicionamentos justificam a proposição de um estudo sobre polígonos voltado para alunos dos anos iniciais do Ensino Fundamental, na medida em que se entende ser importante essa relação estabelecida com os diferentes espaços de vivência dos sujeitos. $\mathrm{O}$ ensino de Geometria é extremamente relevante na vida do aluno como cidadão, uma vez que está ligada à habilidade do sujeito orientarse no espaço.

Neste trabalho, portanto, são investigadas as possíveis aplicações de materiais manipuláveis no ensino de Geometria nos anos iniciais. Serão apresentados os resultados de um dos momentos da aplicação de uma sequência didática sobre polígonos, com ênfase para o uso de materiais manipuláveis.

Trata-se de um recorte de uma dissertação de mestrado já concluída intitulada 
didática para o ensino de polígonos." Foi escolhido o primeiro momento de aplicação da sequência didática por englobar os conceitos de polígonos, objeto central deste estudo.

\section{O USO DE MATERIAIS MANIPULÁVEIS NO ENSINO DE GEOMETRIA}

O objeto de estudo para o qual este artigo encontra-se voltado é o ensino de Geometria como importante conteúdo do ensino de Matemática, cuja amplitude e relevância não podem passar despercebidas. Conforme pontua Pavanello (2004), a Geometria tem potencialidade para desenvolver as capacidades de generalizar, de projetar, pois ela proporciona condições aos estudantes para que alcancem níveis sucessivos de abstração.

Na mesma direção, Lorenzato (1995) ratifica a necessidade do ensino de Geometria a partir do argumento de que este conteúdo permite o desenvolvimento do pensar geométrico ou ainda do raciocínio visual, importantes componentes do desenvolvimento cognitivo. Segundo o autor, "[...] sem conhecer Geometria, a leitura interpretativa do mundo torna-se incompleta, a comunicação das ideias fica reduzida e a visão da matemática torna-se distorcida" (LORENZATO, 1995, p. 5)

Não obstante, na realidade de muitas instituições de ensino, essa compreensão encontra-se distanciada da realidade, uma vez que os conteúdos geométricos deixam de ser contemplados de maneira constante, contínua e de maneira profunda, embora constem na proposta pedagógica dos anos iniciais.

Passos (2000, p. 49) refere-se à Geometria como sendo um dos ramos da Matemática que tem potencial para estimular o aprendizado dessa disciplina, pois pode oferecer oportunidades para que o estudante desenvolva habilidades criativas. Isso ocorre quando o estudante executa atividade de ordenação, classificação de modelos de figuras planas e de sólidos, manipula formas geométricas em software de forma dinâmica, realiza construções com palitos ou varetas ou faz dobraduras.

Em conformidade com as contribuições trazidas por Passos (2000), convém frisar que, para desenvolver as atividades envolvendo Geometria, os professores devem proporcionar aos alunos a oportunidade de manipular alguns objetos. Dessa forma, os alunos começam a perceber suas características, potencializando o estabelecimento de relações básicas e necessárias para entender os conceitos geométricos.

Na mesma linha de pensamento, podem ser apontadas as considerações elaboradas por Dante (2006, p. 34-35), quando esclarece que a Geometria nas séries iniciais deve ser manipulativa, ou experimental. Manipulando objetos ou embalagens, o aluno tem a possibilidade de descobrir diferenças e semelhanças entre eles e diante desse fazer ele descobre, nesses objetos, seus elementos, suas características e propriedades.

Conforme ainda Dante (2005, p. 60), "Devemos criar oportunidades para as crianças usarem materiais manipuláveis [...] A abstração de ideias tem sua origem na manipulação e atividades mentais a ela associados". Isso confirma a necessidade de um trabalho mais intenso com os materiais manipuláveis no ensino 
de Geometria, pois é preciso efetuar a passagem de uma representação para outra, ou seja, do concreto para o abstrato.

Salienta-se que muitas das dificuldades encontradas no ensino de Matemática podem estar relacionadas a falhas nesse processo de abstração de ideias. Assim, o uso de materiais didáticos adequados pode se mostrar uma das respostas a tais entraves no processo de ensino e aprendizagem dessa disciplina.

Lorenzato (2006, p. 22) acredita que "[...] para se chegar no abstrato, é preciso partir do concreto". Segundo ele, conforme a intenção do professor e a forma utilizada, os materiais manipuláveis podem desempenhar diferentes funções, as quais devem ser criteriosamente e previamente selecionadas pelo professor.

Nessa perspectiva, os materiais manipuláveis atuam como elementos de mediação do processo de ensino e de aprendizagem, concepção apresentada por Passos (2006, p. 78): tais recursos "[...] devem servir como mediadores para facilitar a relação professor/aluno/conhecimento no momento em que um saber está sendo construído".

Uma vez que a manipulação de objetos permite aos alunos perceber suas características, potencializando a compreensão dos conceitos geométricos, Oliveira Júnior e Miziara (2014, p. 182) entendem que os materiais concretos ocupam, em todos os níveis de ensino, uma posição estratégica. Assim, podem funcionar como uma ferramenta de diálogo entre os professores e os alunos, uma vez que podem ocupar um espaço importante para que os alunos participem no aperfeiçoamento das estratégias e compreendam os conceitos estudados.

Com ênfase nos anos iniciais do ensino, convém ponderar que os materiais manipuláveis facilitam a observação e análise por favorecerem o desenvolvimento do raciocínio lógico e crítico, essenciais para a construção dos diferentes saberes matemáticos.

Pais $(2013$, p. 17) salienta que os materiais manipuláveis, enquanto recursos de ensino, são criações didáticas, ou seja, "[...] são criações motivadas por supostas necessidades do ensino para servirem como recursos para outras aprendizagens". Isso equivale a afirmar que a inserção dos materiais manipuláveis deve cumprir a finalidade de levar o aluno a formar conceitos e a apropriar-se deles.

Importa, pois, considerar o que questiona Nacarato (2004/2005), ao observar situações práticas de professores em sala de aula e constatar alguns equívocos dos docentes, quando estes não atingem o objetivo de levar os alunos a interagir com o material, fazendo-os perder um longo tempo com desenhos sem explorar o material adequadamente: o uso inadequado de qualquer material manipulável pouco ou nada contribui para a aprendizagem da Matemática.

Nesse ponto da discussão, é oportuno alertar para a prática do uso dos materiais manipuláveis sem o devido conhecimento ou necessário aprofundamento sobre as finalidades de cada tipo de material. Ocorrem ainda situações em que esses recursos são utilizados apenas de forma lúdica, sem que sejam esgotadas todas as suas possibilidades de trabalho.

Retomando Lorenzato (2006, p. 21), este afirma que, conforme os conteúdos matemáticos são conduzidos pelo professor, o material manipulável "[...] pode ser um excelente catalisador para o aluno construir o seu saber matemático". Essa ideia é reforçada por Jesus e Fini (2005), pois apontam para a possibilidade de que 
todos os recursos ou materiais de manipulação que visam atrair os alunos para um aprendizado de Matemática possam ser utilizados como catalisadores com vistas a aumentar a motivação e estimular os alunos a uma aprendizagem com mais qualidade.

Além da melhora na atenção e na concentração, mencionada pelos autores, deve-se ressaltar o envolvimento dos alunos no processo de construção dos saberes geométricos, estimulados pela observação e manipulação de diferentes materiais.

No entanto, sabe-se que a mera utilização dos materiais manipuláveis não garante a aprendizagem de tais saberes. Nessa perspectiva, o papel do professor reveste-se de maior importância, tanto na escolha do material adequado a cada situação de aprendizagem, quanto durante a atividade manipulativa.

Passos (2006) defende a ideia de que o aluno não aprende Matemática simplesmente manipulando objetos, sendo imprescindível a realização de uma atividade mental por parte desse aluno. Faz-se ainda necessária a mediação do professor, a partir do estabelecimento de reflexões sobre a ação manipulativa, as quais, por sua vez, permitem ao aluno o reconhecimento de relações que o levem a pensar, analisar e agir.

No entendimento de Dante (2005), é necessário que sejam desenvolvidas nos estudantes, habilidades para desenvolver seu raciocínio lógico, para que façam uso inteligente e eficaz dos recursos disponíveis, elaborando, assim, soluções favoráveis às questões que surgem no seu cotidiano. Dessa forma, os conceitos geométricos podem ser construídos pelos alunos a partir de uma ação interiorizada, mas, também, conforme aponta Passos (2010), pelo significado que estes atribuem às ações, pelas formulações que enunciam e pelas verificações que realizam.

Uma vez evidenciada a importância do uso de materiais manipuláveis no ensino de Geometria, no tópico a seguir, discorre-se sobre algumas espécies desses materiais.

\section{MATERIAIS MANIPULÁVEIS: DE PAPÉIS E PALITOS À CONSTRUÇÃO DE GEOPLANOS}

Na realização das atividades referentes ao ensino de Geometria para os anos iniciais, podem ser utilizados diferentes materiais manipuláveis, tais como canudos de plástico e palitos de dente, massa de modelar e barbante para construção dos polígonos. Papéis de diferentes cores e espessuras, caixas de diferentes tamanhos e malhas quadriculadas também compõem a lista dos materiais disponíveis para a montagem de figuras geométricas, visando à representação de figuras planas.

Buscando traçar o percurso de utilização desse tipo de material, Godoy e Guirado (2009) mencionam que educadores famosos já evidenciavam, desde o século XIV, a importância do uso de material manipulável. Assim, Comenius (15921670) defendia a ideia de que a aprendizagem tem início pelos sentidos, pois as impressões sensoriais obtidas através da experiência com objetos seriam internalizadas e, mais tarde, interpretadas pela razão. Por esse viés, corrobora-se a percepção de que o ensino da Matemática deve se dar do concreto para o 
abstrato, posição também reconhecida por Pestalozzi (1746-1827) e Froebel (1782-1852), quando reconhecem a importância dos materiais manipuláveis.

Não obstante, entende-se que a mera presença desses materiais em sala de aula não garante a aprendizagem, uma vez que a construção do conhecimento matemático não ocorre apenas pela manipulação dos objetos. É importante que o professor proponha questões adequadas, que levem o aluno a observar os aspectos do material relevantes para a construção dos conceitos.

Essa mesma percepção pode ser vislumbrada em Camacho (2012). A autora salienta que os materiais manipuláveis são objetos didáticos intuitivos e dinâmicos que visam à compreensão de diversos conceitos. Em qualquer fase do desenvolvimento escolar, podem conduzir ao processo de descoberta, pois, em contato direto com esse tipo de material, o aluno tem condições de explorar e investigar situações, aprendendo a comunicar-se, a raciocinar e a resolver situações problemas de uma forma mais natural e clara.

No processo de descoberta de que trata Camacho (2012), encontra-se a maior justificativa para o uso de materiais manipuláveis, na medida em que são objetos lúdicos, dinâmicos e intuitivos, colaborando como apoio para que os estudantes possam atingir o grau de abstração necessário para a formação de conceitos matemáticos e/ou geométricos.

É importante salientar que o uso de materiais concretos/manipuláveis pode proporcionar muitos benefícios, como, por exemplo, desenvolver capacidades e atitudes que propiciem um maior envolvimento com a própria aprendizagem. Espera-se que, a partir da utilização adequada dos materiais manipuláveis, os estudantes possam buscar novos caminhos para a observação, procura e reflexão e que promovam um envolvimento ativo ao estruturar seus próprios conceitos.

Também sob a perspectiva de Rêgo e Rêgo (2010, p. 43), por meio da manipulação de materiais, "[...] os alunos ampliam sua concepção sobre o que é, como e para quê aprender matemática, vencendo os mitos e preconceitos negativos, favorecendo a aprendizagem pela formação de ideias e modelos".

É possível sinalizar, ainda, para uma potencial melhora do raciocínio matemático, na medida em que os materiais manipuláveis permitem desenvolver os aspectos cognitivos e psicomotores, transformando o ensino-aprendizagem da Matemática em uma prática dinâmica, intuitiva e desafiante.

Lorenzato (2010) frisa que os materiais manipuláveis constituem uma variação dos materiais didáticos e estabelece distinção entre os materiais manipuláveis estáticos e os dinâmicos. No primeiro grupo, situam-se os materiais que não possibilitam modificações em suas formas, como os sólidos geométricos construídos em madeira ou cartolina, o ábaco, o material montessoriano (cuisenaire ou dourado) e os jogos de tabuleiro. Por sua vez, os materiais dinâmicos são aqueles que permitem transformações por continuidade e facilitam ao aluno a realização de redescobertas, a percepção de propriedades e a construção de uma efetiva aprendizagem.

Estendendo o rol dos materiais manipuláveis, cabe ainda observar o que afirmam Pereira e Oliveira (2016), que entendem como materiais manipuláveis "[...] uma folha de papel, uma régua, uma tesoura", ou seja, todos os materiais que 
o professor pode usar para trabalhar ideias matemáticas e favorecer a elaboração de conjecturas sobre qualquer tópico da Matemática.

Independente da espécie do material selecionado, convém ponderar que sua escolha depende do conteúdo a ser trabalhado e, nessa dimensão, o papel do professor mostra-se determinante. No entanto, Lorenzato (2010) reflete sobre o fato de que uma das críticas mais frequentes ao uso dos materiais manipuláveis refere-se ao tempo gasto para explorar adequadamente tais recursos. $\mathrm{O}$ autor ressalta que o uso desse tipo de material pode inicialmente tornar o ensino mais lento, mas, em seguida, graças à compreensão adquirida pelo aluno, o ritmo aumentará e o tempo gasto no início será largamente recompensado em quantidade e principalmente em qualidade.

Esse mesmo autor argumenta que os resultados da utilização de materiais manipuláveis compensam o tempo dispendido, na medida em que potencializam a construção do pensamento matemático dos alunos.

Destaca-se, ainda, que não existe um material específico para se trabalhar um determinado conceito, podendo o mesmo conteúdo ser trabalhado por meio de diferentes materiais. Sendo assim, no caso da Geometria, é possível utilizar o geoplano, o Tangram, embalagens diversas, a régua, o esquadro e outros materiais que também se mostram úteis para desenvolver os conceitos matemáticos.

Silva e Martins (2000) compartilham dessa visão e acrescentam que esses materiais são fundamentais, pois ajudam a criança na passagem do concreto para o abstrato, conforme vão sendo usados como um suporte físico em situações de aprendizagem, na resolução de situações-problema.

O que está em evidência em relação aos materiais manipuláveis é o gosto pela descoberta, pela experimentação e pela construção e reconstrução de conceitos. Nesses moldes, a utilização de materiais manipuláveis no processo ensino aprendizagem da Matemática e, de maneira mais específica, da Geometria, pode contribuir, de fato, para a construção de experiências lúdicas, dinâmicas e enriquecedoras.

Para Oshima, Ottesbach e Pavanello (2008), o uso de material manipulável precisa ser objeto de um planejamento adequado, que conduza à seleção de estratégias e ao questionamento necessário à exploração de todo seu potencial. As autoras sugerem ainda que as atividades sejam previamente testadas para que a manipulação do material contribua realmente para a construção dos conceitos. Ressaltam ainda que os conhecimentos matemáticos são de natureza abstrata, portanto a passagem de ações concreta para a elaboração dos conceitos matemáticos deve ser contemplada com atenção pelo professor, buscando estabelecer a correlação entre os dois domínios envolvidos, o do material concreto utilizado e o das representações simbólico-abstratas.

A partir dos materiais manipuláveis é possível haver observação, manipulação e exploração dos objetos reais ou próximos do real, possibilitando construção e reconstrução, além de proporcionar a formação de conceitos geométricos (MACIEL, 2010).

Nessa direção, a utilização de materiais manipuláveis apresenta-se como uma necessidade para o ensino da disciplina, podendo ser mencionados jogos, tais 
como dominó, Tangram e varetas, além de outros tipos, tais como embalagens diversas, blocos lógicos, material dourado, sólidos geométricos e geoplanos.

Conforme Passos (2010), há uma infinidade de materiais que podem ser usados para apresentar situações que levem os alunos a conjecturar, formular soluções, elaborar novas perguntas, descobrir estruturas, enfim fazê-los refletir, por intermédio das atividades propostas, pois os conceitos vão sendo formados pela ação interiorizada dos alunos sobre o material que manipulam e pelo significado atribuído às ações.

Além disso, encontra-se em Pais (2015) a percepção de que atividades como construir, medir, desenhar, compor e decompor, comparar e classificar figuras geométricas mostram-se essenciais para a construção dos conceitos geométricos. Também Dante (2006) afirma que é manipulando os objetos, como dados, esfera, cones, tampinhas, bolinhas de gude, rolinhos de papéis e diversos tipos de embalagens, entre outros, que o aluno descobre seus elementos, suas caraterísticas, suas diferenças e as semelhanças, podendo assim ter arcabouço para elencar propriedades.

Portanto, para desenvolver as atividades envolvendo Geometria, os professores devem buscar proporcionar aos alunos a oportunidade de manipular alguns objetos, pois, dessa forma, começam a perceber suas características, potencializando o estabelecimento das relações básicas e necessárias para entender os conceitos geométricos.

Um dos materiais que permitem o trabalho manipulável é o geoplano. Com ele $\mathrm{o}$ aluno pode construir, desfazer e alterar facilmente suas construções, favorecendo a exploração. Trata-se de um objeto construído em madeira, no formato de um tabuleiro quadrangular, sobre o qual são afixados pregos, pinos ou parafusos equidistantes entre si. Seu manuseio requer o uso de barbantes, elásticos ou outras espécies de fios que devem ser acoplados aos pregos, formando diversas figuras geométricas planas, com a finalidade de permitir uma flexibilidade, para discutir suas propriedades e características.

Este é um material concebido para trabalhar diversos conceitos, que se
encontram incluídos nos temas da álgebra, da Geometria e dos números e
operações, cuja manipulação permite calcular e fazer previsões, de forma a
otimizar todo o processo de exploração e descoberta, realizados pelo próprio
aluno. Foi criado pelo matemático inglês Caleb Gattegno e é constituído por
um tabuleiro com pregos, dispostos em quadrado, formando uma espécie de
quadriculado. (CAMACHO, 2012, p. 38).

Na figura a seguir, pode ser observado um dos muitos modelos de geoplano que podem ser construídos a partir de material de baixo custo. 
Figura 1 - Representação de polígonos no geoplano

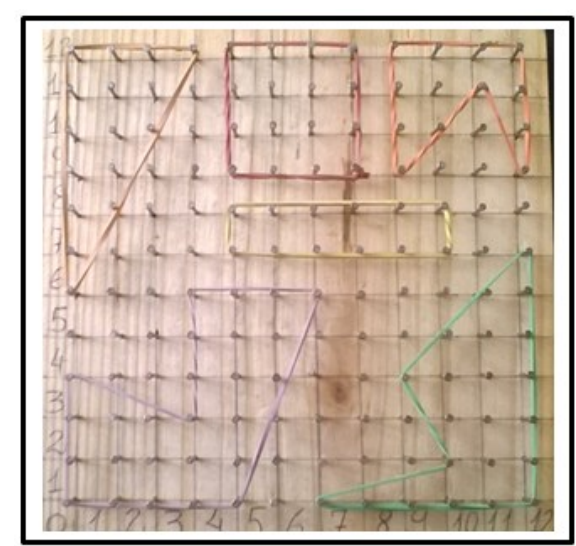

Fonte: autoria própria (2017).

Gattegno (1967 apud FREITAS, 2004) propôs que todos os geoplanos têm indubitável atrativo estético e podem proporcionar experiências geométricas a crianças desde cinco anos, por meio da proposição de problemas "[...] de forma, dimensão, de simetria, de semelhança, de teoria dos grupos, de Geometria projetiva e métrica que servem como fecundos instrumentos de trabalho, qualquer que seja o nível de ensino" (GATTEGNO, 1967 apud FREITAS, 2004, p. 55).

Parte-se do pressuposto de que a utilização de materiais manipuláveis se apresenta como uma necessidade para o ensino de Matemática, conforme sustenta Nacarato (2004/2005), que considera fundamental seu uso em qualquer nível de ensino, por considerar que a utilização de materiais como o Tangram, geoplano, poliminós e conjunto de sólidos geométricos podem contribuir no processo de desenvolvimento da visualização dos alunos.

Ademais, a utilização de materiais manipuláveis não requer um custo elevado, já que podem ser utilizados até mesmo materiais destinados à reciclagem, e as vantagens para construção dos saberes geométricos mostram-se evidentes.

\section{METODOLOGIA}

Conforme já mencionado, este artigo representa um recorte de uma dissertação de mestrado que utilizou como instrumento de pesquisa uma sequência didática aplicada a alunos de um 50 ano do Ensino Fundamental I de uma escola da rede municipal de ensino de Londrina/PR. A aplicação da sequência didática foi realizada no primeiro semestre letivo do ano de 2017. A turma selecionada era composta por 17 alunos, sendo 7 do sexo feminino e 10 do sexo masculino, com idades compreendidas entre 9 e 11 anos. A previsão inicial foi de 30 aulas, distribuídas em 2 horas diárias, durante 3 dias por semana, totalizando um período aproximado de 45 dias.

A construção da sequência didática teve como propósito a superação das dificuldades apresentadas por alunos quanto aos conceitos e aspectos relacionados aos polígonos. Essa sequência incluía 7 diferentes etapas, denominadas momentos, cada qual com uma série de atividades em torno dos conteúdos de polígonos. 
Neste artigo, optou-se por discorrer sobre os resultados do primeiro momento, cujo objetivo foi a exploração das características dos polígonos, tendo em vista a construção de seu conceito.

\section{RESULTADOS E DISCUSSÃO}

No primeiro momento da sequência didática que constituiu a parte prática da dissertação de mestrado, da qual derivou o presente artigo, foram utilizados diferentes materiais manipuláveis. As cinco atividades que compuseram esse momento tiveram como finalidade levar os alunos a descobrir as principais propriedades definidoras dos polígonos.

Na primeira atividade, após ser entregue uma folha impressa com seis faixas contendo diferentes tipos de figuras, os alunos, organizados em duplas, deveriam identificar, em cada faixa, a figura que julgassem não pertencer ao conjunto das demais.

Figura 2- Atividade de observação e reconhecimento de figuras

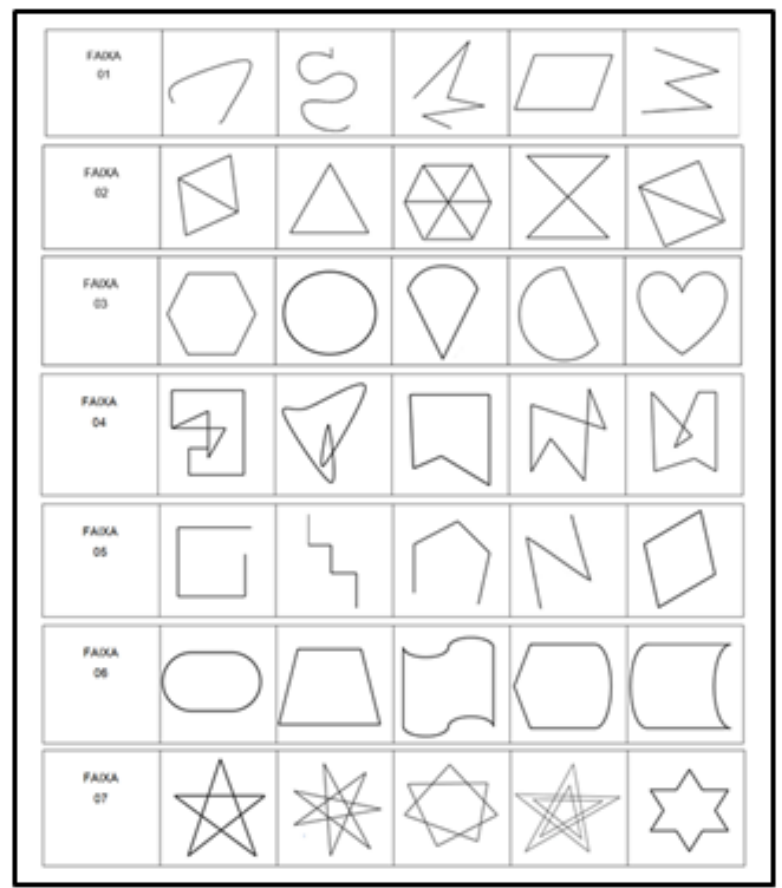

Fonte: adaptado de Toledo e Toledo (2009).

Na faixa 1, representando $75 \%$ do total de alunos que realizaram a atividade, 7 duplas sinalizaram o paralelogramo como figura diferente e apenas 1 grupo, perfazendo $12,5 \%$ do total da amostra, apontou uma linha curva como diferente.

Na faixa 2, o triângulo foi apontado por 4 duplas (50\%), enquanto 3 grupos $(37,5 \%)$ apontaram a figura que correspondia a 2 triângulos sobrepostos e 1 dupla $(12,5 \%)$ considerou diferente o hexágono dividido em linhas que se cruzam. $\mathrm{Na}$ terceira faixa, houve apenas 1 dupla (12,5\%) que não conseguiu identificar a figura diferente, apontando a 4a figura da faixa, que possuía curva e linha reta.

$\mathrm{Na}$ 4a faixa, o pentágono irregular foi identificado como diferente por 5 grupos $(62,5 \%)$, sendo que 3 duplas $(37,5 \%)$ apontaram a 2 a figura da faixa como 
diferente, composta com curvas cruzadas. Quanto à faixa 5, o losango foi apontado corretamente por 6 grupos (75\%), enquanto 2 duplas (25\%) sinalizaram como diferente a 4 a figura da faixa, composta por linhas abertas.

Na sexta faixa, 6 grupos (75\%) identificaram o trapézio como diferente, enquanto os demais grupos apontaram a 3a figura, composta por curvas e retas. Na sétima e última faixa, 6 duplas (75\%) sinalizaram corretamente o dodecágono irregular, enquanto 2 duplas (25\%) assinalaram a 3a figura, em que havia a superposição de 2 quadriláteros.

Os resultados obtidos foram satisfatórios, pois, em 6 faixas, a grande maioria dos alunos conseguiu identificar a figura diferente, sendo que apenas na 2 a faixa a taxa de respostas adequadas ficou em $50 \%$. O resultado não foi previsível, pois, nessa faixa, a figura diferente seria o triângulo, cuja noção é trabalhada desde a Educação Infantil.

Sobre a nomenclatura das figuras, grande parte das duplas não apresentou respostas adequadas, sendo o triângulo mencionado por 4 duplas, o hexágono identificado por apenas 1 dupla, o losango apontado por 1 dupla, enquanto o trapézio foi reconhecido por 2 duplas. As duplas deveriam ainda explicar por que a figura selecionada como diferente não fazia parte do grupo. As respostas dadas foram bastante variadas. A Figura 3 demonstra as respostas de um dos grupos para exemplificar o pensamento geométrico dos alunos. 
Figura 3 - Atividade desenvolvida por uma das duplas

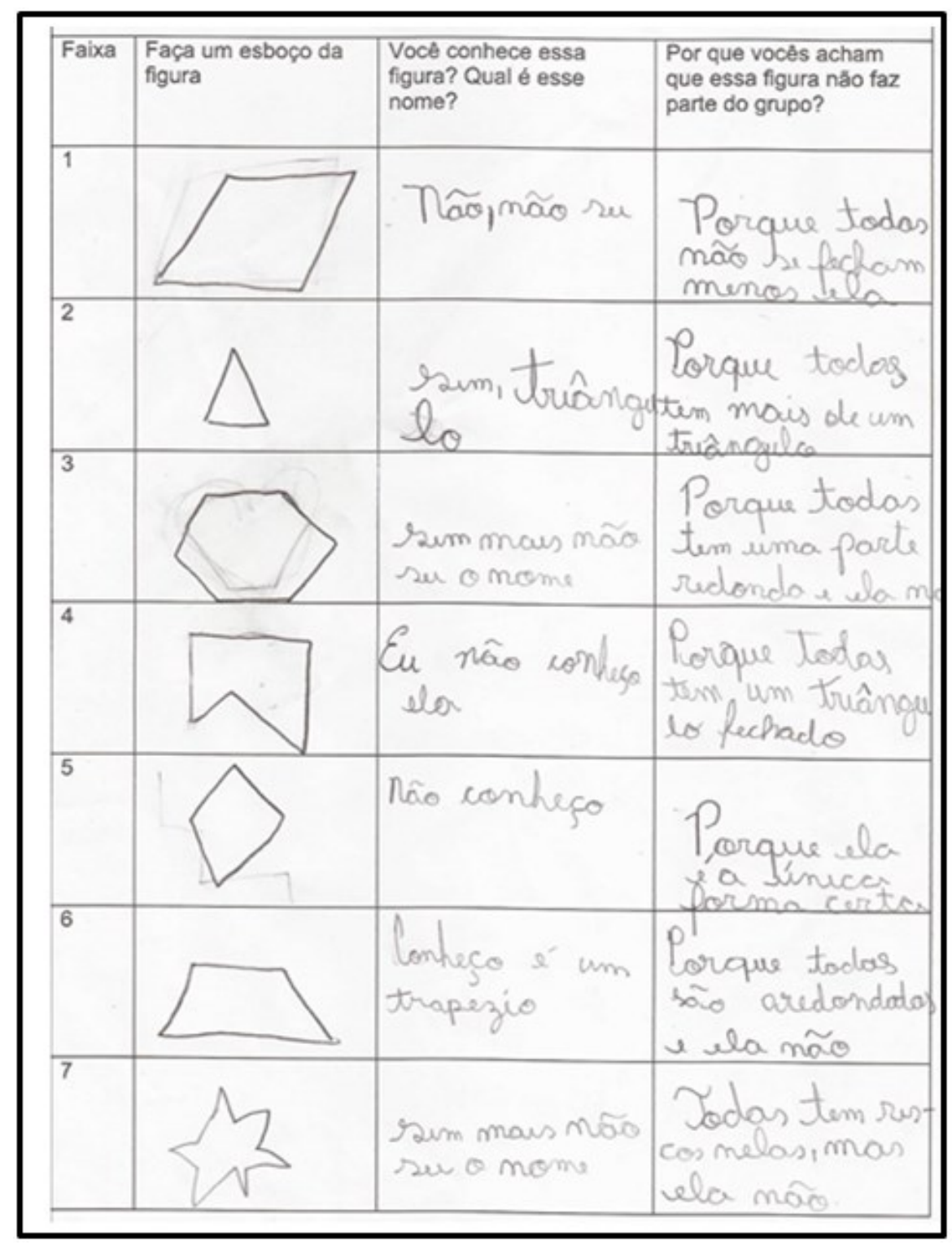

Fonte: autoria própria (2017).

A dupla soube levantar as características das figuras de forma satisfatória. Trata-se de um exemplo interessante, pois mostra que as alunas utilizaram a visualização para comparar as figuras, o que corresponde à proposta de ensino presente nos Parâmetros Curriculares Nacionais, quando afirmam que "[...] o pensamento geométrico desenvolve-se inicialmente pela visualização: as crianças conhecem o espaço como algo que existe ao redor delas" (BRASIL, 1997, p. 82).

As respostas sobre a nomenclatura das figuras permitiram identificar a posição de uma das integrantes do grupo, sobretudo em relação ao trapézio, figura reconhecida de maneira adequada pela dupla, embora menos usual que o triângulo, a outra forma geométrica sinalizada. Quando questionadas, uma das alunas disse que se lembrava de ter estudado no anterior.

Em muitas situações, a professora sugeriu que os alunos buscassem a opinião dos colegas do grupo como forma de estimular o trabalho coletivo. Houve outros 
grupos que, embora tenham identificado corretamente a figura diferente, não expressaram de forma adequada as características distintivas entre as figuras.

Na segunda parte da atividade, os alunos deveriam recortar de cada faixa a figura considerada diferente e colar em outra folha impressa, relacionando as características em comum.

Em relação a todas as faixas, 4 duplas, ou seja, 50\% do total de alunos que realizaram a atividade, apontaram corretamente todas as figuras diferentes em cada grupo, apesar de terem apresentado conceitos distintos, tais como: "É que são iguais e têm as mesmas características"; "Elas têm pontas e parece que nas pontas têm um triângulo"; "Têm linhas retas, são todas fechadas, nenhuma tem risco no meio".

A discussão dessas respostas pode auxiliar na institucionalização local, explicitada por Artigue (2009) como a fase em que o professor expõe o que é novo a ser retido, apresentando definições, teoremas, demonstrações, apontando o que é essencial e secundário. Dias e Mateus (2017) a denominam também de explicitação e nela os alunos colocam em evidência os conhecimentos que surgiram, em conflito com os que já possuíam. As contradições devem ser resolvidas com ou sem a intervenção do professor. Ocorre, no entanto, que, no contexto cotidiano de sala de aula, nem sempre é possível ao professor retomar a institucionalização local para firmar os conceitos, em virtude das demandas do tempo escolar.

No que diz respeito aos alunos que não identificaram todas as figuras diferentes de cada faixa, foram dadas justificativas, como "Elas têm curvas e retas"; "Porque elas têm linhas retas e bastante curva"; "Todas têm os lados retos e são fechadas" e "Todas têm formas de triângulo".

As justificativas encontradas permitem afirmar que as duplas não conseguiram elaborar corretamente seu pensamento com base na visualização das figuras. É conveniente mencionar que a professora enfatizou o fato de os alunos poderem, ao recortarem as figuras diferentes de cada faixa, substituir alguma que não correspondesse às demais na medida em que estava sendo formado um novo conjunto que deveria ter características comuns. Apenas um grupo trocou uma figura, porém o fez de maneira inadequada.

Figura 4 - Processo de realização da Atividade 1

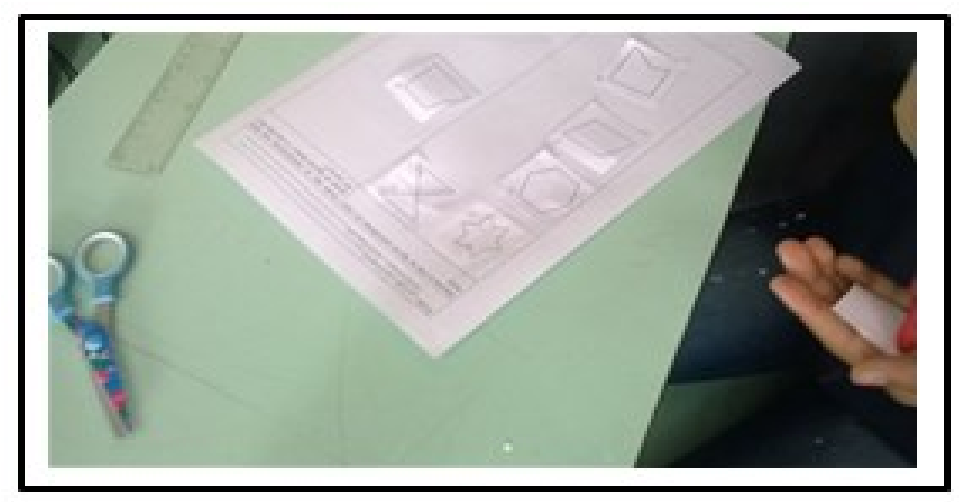

Fonte: autoria própria (2017). 
Diante dos resultados descritos, foi possível observar que alguns alunos não possuíam suporte teórico para realizar essa tarefa, uma vez que ainda se encontravam no processo de visualização e muitos não conseguiram relacionar de forma adequada às propriedades do objeto matemático.

A socialização dos resultados permitiu a apresentação das características dos polígonos por meio da análise das respostas dos grupos que apontaram as figuras corretas em cada faixa. Depois, as figuras foram desenhadas no quadro e as características de linhas retas, fechadas e que não se cruzam foram destacadas.

Em uma aula posterior, os alunos, também organizados em grupos, procederam à construção de vários polígonos, usando 24 palitos de tamanhos diferentes e massinha de modelar. Além disso, receberam orientação para mudar de grupos, a fim de observar o que fora realizado pelos colegas. De volta aos grupos originais, foram lançadas questões sobre o desenvolvimento do trabalho e foi apresentada pela professora a noção de vértices e de ângulos.

Figura 5 - Construção de polígonos com palitos

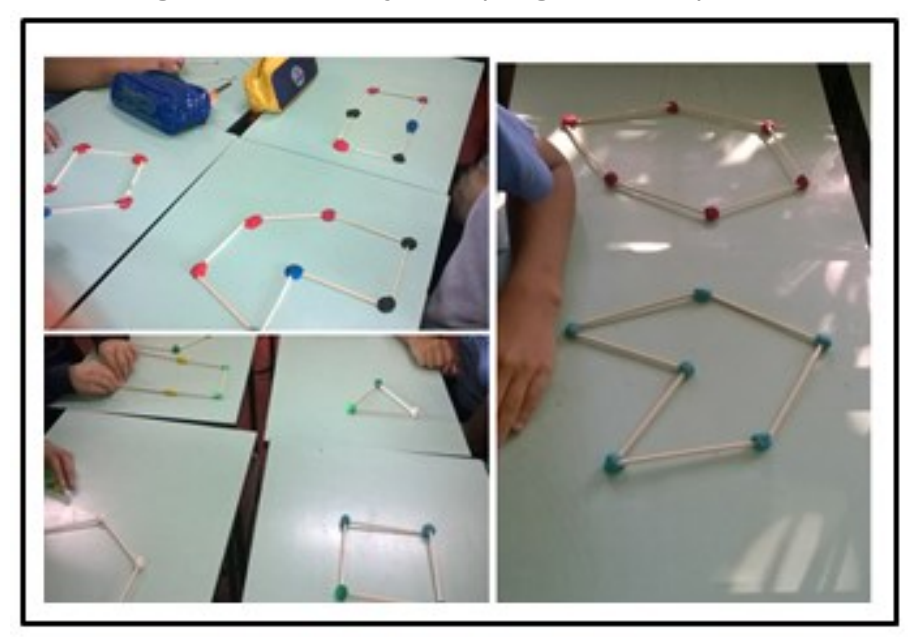

Fonte: autoria própria (2017).

Os alunos ainda responderam sobre o número de lados nas figuras formadas e chegaram à conclusão de que a quantidade mínima necessária era de três lados e que não há número máximo. Após essa etapa, deveriam fazer um esboço da figura criada, completando as informações da tabela quanto ao número de lados, de vértices, ângulos e expressando suas concepções sobre o trabalho realizado.

As instruções foram precisas quanto ao fato de que os grupos deveriam utilizar todos os 24 palitos e lembrar das características dos polígonos. No entanto, foram observadas diferenças na forma de construção, pois 2 grupos construíram 4 figuras, enquanto os 2 outros grupos formaram 5 figuras, incluindo o triângulo em sua representação. Um dos grupos merece destaque, já que os integrantes utilizaram igual quantidade de palitos para cada figura (6 palitos), resultando em figuras diferentes.

Dois grupos conseguiram identificar que os lados e ângulos das figuras formadas eram iguais. Todos definiram corretamente a quantidade mínima de lados para formar um polígono. 
Para finalizar esse momento, em outra aula, foram distribuídas figuras diversificadas aos grupos, sendo solicitado que classificassem em polígonos e não polígonos. Os alunos confeccionaram cartazes e acrescentaram uma definição de polígono após pesquisa em dicionários de diferentes autores. A atividade permitiu fixar as características dos polígonos e ficou claro que as dúvidas com relação à necessidade de haver apenas linhas retas permaneciam.

Figura 6 - Atividade com polígonos e não polígonos

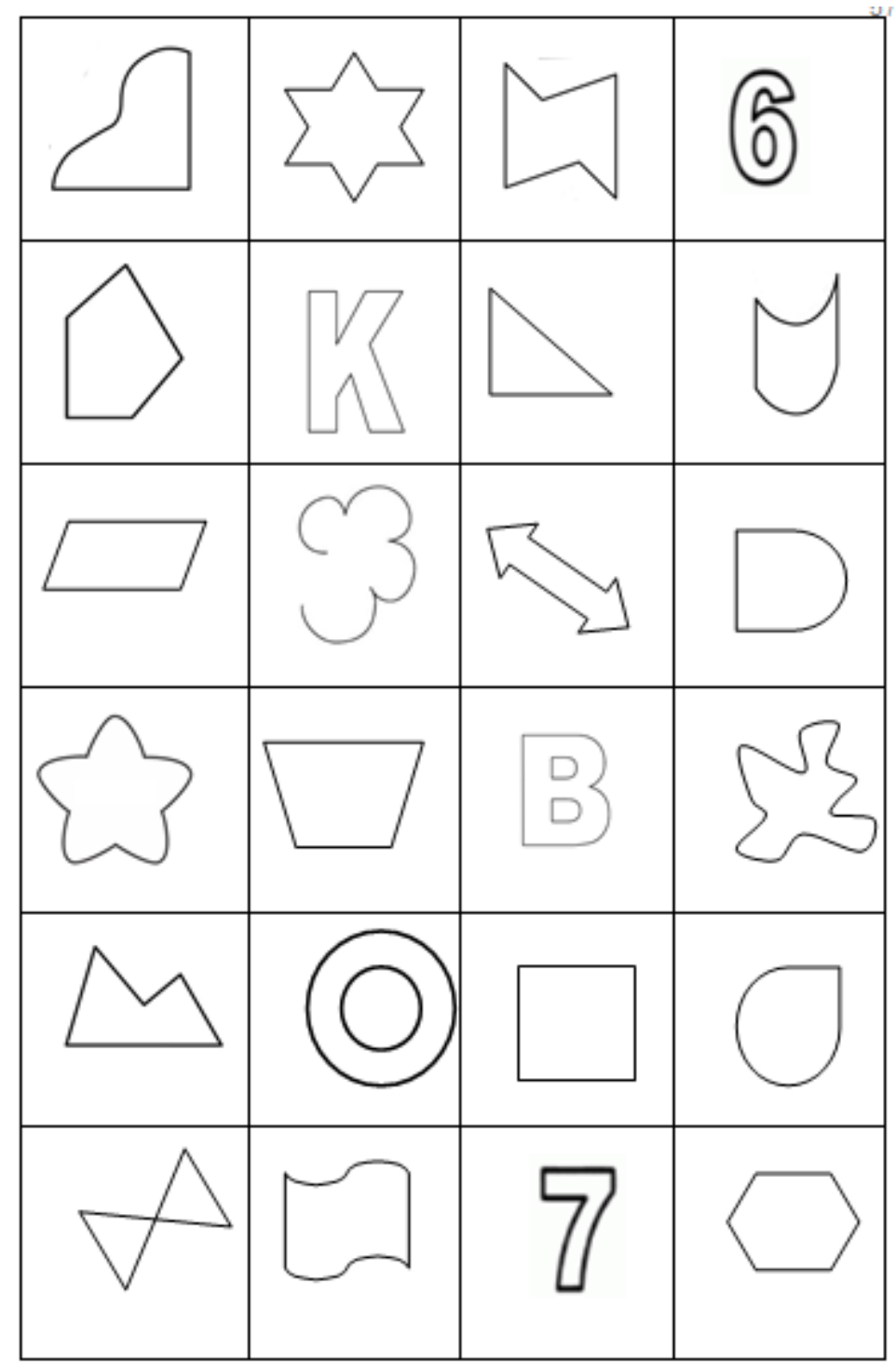

Fonte: autoria própria (2017).

Os alunos demonstraram dificuldade especificamente em relação a duas figuras (M Várias duplas não as classificaram como polígonos, necessitando de intervenção para observar que eram figuras formadas por linhas retas fechadas e que não se cruzam, portanto, tratava-se de polígonos. Assim, apesar da ênfase dada ao processo visual, foi preciso institucionalizar a noção de polígono. 
Figura 7 - Processo de elaboração de cartazes pelas duplas

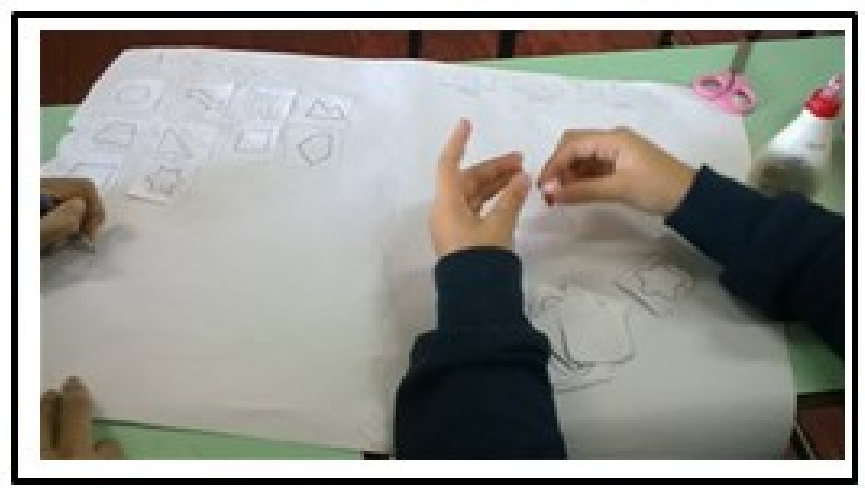

Fonte: autoria própria (2017).

A pesquisa em dicionário também representou uma dificuldade, mas foi transposta com o auxílio da professora. Os cartazes elaborados pelas equipes foram afixados em painel no corredor da escola.

Concluindo o primeiro momento da sequência didática, foi possível observar que o objetivo inicial de levar os alunos a observar e representar as características dos polígonos foi cumprido de forma satisfatória, sendo observada, porém, a necessidade de maior aprofundamento sobre suas propriedades.

Diante dos resultados do primeiro momento da sequência didática, ressaltase a importância de utilização de metodologias adequadas, conforme postulam Lorenzato (1995) e Pavanello (1993), na medida em que as atividades que constituíram a etapa em questão permitiram aos alunos manipular, comparar, recortar, pesquisar, observar e construir o conceito de polígonos.

Reitera-se, assim, a multiplicidade de situações que envolvem o estudo dos polígonos como um componente curricular que pode contribuir para a construção do pensamento geométrico dos alunos. Ao término do primeiro momento, convém ressaltar que os alunos evidenciaram grande interesse pelas atividades desenvolvidas e confirmaram o que afirma Fainguelernt (1999): a Geometria constitui um campo da Matemática que propicia a abstração de mundo, necessária para o desenvolvimento do pensamento geométrico.

Entretanto, nem todos os alunos da turma em que foi aplicada a sequência didática apresentaram o nível de abstração necessário para a compreensão do conceito de polígonos, razão pela qual se confirma a importância de explorar os materiais manipuláveis nas atividades cotidianas em sala de aula, não esquecendo a passagem do concreto para o abstrato.

Finalizando esse momento, é possível ratificar a importância de um trabalho com materiais manipuláveis para a construção dos conceitos geométricos, em conformidade com o pensamento de Fainguelernt (1999, p. 49), quando pontua que "A Geometria exige do aprendiz uma maneira específica de raciocinar, uma maneira de explorar e descobrir [...]".

Trata-se, pois, de um caminho para desenvolver o pensamento espacial e o raciocínio ativado pela visualização, recorrendo à intuição, à percepção e à representação, habilidades essenciais para a leitura do mundo (FAINGUELERNT, 1999). 
A partir dessa perspectiva, é possível confirmar a relevância do desenvolvimento de um trabalho com materiais manipuláveis, tendo em vista a possibilidade de desenvolvimento do pensamento espacial e do raciocínio.

\section{CONSIDERAÇÕES FINAIS}

Este trabalho, cujo objetivo geral consistiu em investigar as possíveis aplicações de materiais manipuláveis no ensino de Geometria nos anos iniciais, apresenta-se como um recorte de uma pesquisa maior, que buscou ver o desenvolvimento do pensamento geométrico do aluno.

Quanto à utilização dos materiais manipuláveis no ensino de Geometria, os autores que sustentam esta revisão bibliográfica confirmam a grande contribuição desses materiais para a construção do conhecimento, uma vez que os conceitos geométricos podem ser construídos pelos alunos a partir de uma ação interiorizada, com a mediação do professor.

O uso de metodologias adequadas exige do professor tempo para preparo e organização do material necessário, bem como requer uma mudança no comportamento dos alunos, que passam de meros expectadores para atores do processo de ensino aprendizagem. Observa-se, então, que dessa forma os alunos realizam as ações e o professor assume a função de mediador da situação. Essa mudança é necessária e vem sendo indicada por diversos pesquisadores de Educação Matemática.

$\mathrm{Na}$ articulação entre os aportes teóricos que embasam este artigo e os resultados encontrados a partir da realização das atividades que compuseram o primeiro momento da sequência didática, foi possível constatar que o uso de materiais manipuláveis se apresenta como uma possibilidade de imprimir maior significado à construção dos conceitos geométricos, na medida em que permitem aos alunos manipular, comparar, recortar, pesquisar, observar e construir conceitos.

Foi possível ainda constatar que os materiais manipuláveis facilitam a observação e análise por favorecerem o desenvolvimento do raciocínio lógico e crítico, essenciais para a construção dos diferentes saberes matemáticos. Dessa forma, parte-se da utilização desse tipo de recurso para aprimorar a aprendizagem de Geometria e, sobretudo, para consolidar a aquisição dos conceitos da Matemática. 


\title{
A didactic sequence for the teaching of polygons: the use of manipulable materials in the fifth grade of the elementary school
}

\begin{abstract}
This paper resulted from a master's research part on the development of the student's geometric thinking. The study focused on the study of polygons aiming to investigate the possible applications of manipulable materials for teaching Geometry in the $5^{\text {th }}$ grade of elementary school. This is a qualitative approach in which we present the results of one of the moments when the didactic sequence on polygons was applied. The theoretical basis is based on authors such as Lorenzato (1995), who advocates the presence of geometry for teaching mathematics based on the argument that this knowledge must be built since child education, since it helps in solving everyday problems, which are often geometrized. The results point out the possibility that manipulable materials can potentiate the construction of geometric knowledge in students of the $5^{\text {th }}$ grade of elementary school. In addition, it was found that the use of manipulable materials presents itself as a possibility to give greater meaning to the construction of geometric concepts, since they allow students to manipulate, compare, cut, search, observe and construct concepts. Evidence that this type of material facilitates observation and analysis by favoring the development of logical and critical reasoning, essential for the construction of different mathematical knowledge.
\end{abstract}

KEYWORDS: Mathematics teaching. Geometry. Manipulable materials. 


\section{AGRADECIMENTOS}

Agradecemos à CAPES pela concessão da Bolsa durante o desenvolvimento desse estudo.

\section{REFERÊNCIAS}

BRASIL. Parâmetros Curriculares Nacionais: Matemática. Brasília: MEC,/SEF, 1997.

CAMACHO, M. S. F. P. Materiais manipuláveis no processo ensino/aprendizagem da Matemática. Aprender explorando e construindo. 2012. Dissertação (Mestrado em Ensino de Matemática) - Universidade da Madeira, Madeira, 2012.

DANTE, L. R. Didática da Resolução de Problemas de Matemática. 12 ed. São Paulo, 2005.

DANTE, L. R. Vivência e construção: Matemática. 3ạ série. 2 ed. São Paulo: Ática, 2006.

FAINGUELERNT, E. K. Educação matemática: representação e construção em Geometria. Porto Alegre: Artes Médicas Sul, 1999.

FREITAS, R. C. O. Um ambiente para operações virtuais com o material dourado. 2004. Dissertação. (Mestrado em Informática) - Universidade Federal do Espírito Santo, Vitória, 2004.

GODOY, A. M. S.; GUIRADO, J. C. Grandezas e medidas do cotidiano no contexto escolar. Curitiba: SEED, 2009. Disponível em:

<http://www.diaadiaeducacao.pr.gov.br/portals/pde/arquivos/248-4.pdf>. Acesso em: set., 2016.

JESUS, M. A. S/ de; FINI, L. D. T. Uma proposta de aprendizagem significativa de matemática através de jogos. In: BRITO, M. R. F. de (Org.). Psicologia da Educação Matemática: teoria e pesquisa. Florianópolis: Insular, 2005. p. 129-146

LORENZATO, S. A. Laboratório de ensino de matemática e materiais didáticos manipuláveis. In: LORENZATO, S. A. (Org.). O laboratório de ensino de matemática na formação de professores. Campinas: Autores Associados, 2006. p. 3-37. 
LORENZATO, S. A. Laboratório de ensino de matemática e materiais didáticos manipuláveis. In: LORENZATO, S. A. (Org.). O laboratório de ensino de matemática na formação de professores. Campinas: Autores Associados, 2010. p. 3-37.

LORENZATO, S. A. Por que não ensinar Geometria? Educação Matemática em Revista, Blumenau: SBEM, ano 3, n. 4, p. 3-13, 1995.

MACIEL, E. M. M. A Geometria nos palitos de fósforo e canudos. In: ENCONTRO NACIONAL DE EDUCAÇÃO MATEMÁTICA, 10, 2010, Salvador. Anais... Salvador: ENEM, 2010.

MIORIM, M. A.; FIORENTINI, D. Uma reflexão sobre o uso de materiais concretos e jogos no ensino de Matemática. Boletim da SBEM-SP, São Paulo: SBEM/SP, a. 4, n. 7, p. 5-10, 1990.

NACARATO, A. M. Eu trabalho primeiro no concreto. Revista da Educação Matemática, São Paulo: SBEM, v. 9 , n. 9 e 10, p. 1-6, 2004-2005.

NACARATO, A. M.; PASSOS, C. L. B. A Geometria nas séries iniciais: uma análise sob a perspectiva da prática pedagógica e da formação de professores. São Carlos: EdUFSCar, 2003.

OLIVEIRA JÚNIOR, A. P. de; MIZIARA, E. L. Concepção e prática de professores de Matemática em relação ao ensino de Geometria no Ensino Fundamental. Ensino Em Re-Vista, v. 32, n.1, p. 175-188, jan./jun. 2014.

OSHIMA, I. S.; OTTESBACH, R. C.; PAVANELLO, R. M. O laboratório de ensino e aprendizagem de Matemática (LEM). Curitiba: SEED, 2008. Disponível em: < https://goo.gl/hyGLqj >. Acesso em: set., 2016.

PAIS, L. C. Ensinar e aprender matemática. 2 ed. Belo Horizonte: Autêntica, 2013.

PAIS, L. C. Didática da Matemática: uma análise da influência francesa. Introdução. 3 ed. Belo Horizonte: Autêntica, 2015.

PASSOS, C. L. B. Representações, interpretações e prática pedagógica: a Geometria na sala de aula. 2000. Tese (Doutorado em Educação) - Universidade Estadual de Campinas, Campinas, 2000. 
PASSOS, C. L. B. Materiais manipuláveis como recursos didáticos na formação de professores de matemática. In: LORENZATO, Sérgio (Org.). O Laboratório de ensino de matemática na formação de professores. Campinas: Autores Associados, 2006.

PAVANELLO, R. M. Por que ensinar/aprender Geometria? In: ENCONTRO PAULISTA DE EDUCAÇÃO MATEMÁTICA, 7, 2004, São Paulo. Anais... São Paulo, 2004.

PAVANELLO, R. M. O abandono do ensino de Geometria no Brasil: causas e consequências. Zetetiké, v.1, n.1, 1993, p. 1-17.

PEREIRA, J. S.; OLIVEIRA, A. M. P. de. Materiais manipuláveis e engajamento de estudantes nas aulas de matemática envolvendo tópicos de Geometria. Ciênc. Educ., Bauru, v. 22, n. 1, p. 99-115, 2016.

PONTE, J. P. Investigações matemáticas na sala de aula. Belo Horizonte, MG: Autêntica, 2005.

REGO, R. M. do; RÊGO, R. G. do. Desenvolvimento e uso de materiais didáticos no ensino de Matemática. In: LORENZATO, Sérgio (Org.). O Laboratório de ensino de matemática na formação de professores. Campinas: Autores Associados, 2010, p. 39- 56.

SILVA, A.; MARTINS, S. Falar de Matemática hoje é... Millenium - Revista do ISPV, n. 20, out. 2000. Disponível em: <http://www.ipv.pt/millenium/20_ect5.htm>. Acesso em: ago., 2016.

TOLEDO, M.; TOLEDO, M. Teoria e prática da matemática: como dois e dois. São Paulo: FTD, 2009.

Recebido: 12 mar. 2018

Aprovado: 23 jul. 2018

DOI: $10.3895 /$ actio.v3n3.7897

Como citar:

POLLI, C. T. da S.; FIGUEIREDO, H. R. F. Uma sequência didática para o ensino de polígonos: o uso de materiais manipuláveis no quinto ano do ensino fundamental. ACTIO, Curitiba, v. 3, n. 3, p. 378-398,

set./dez. 2018. Disponível em: <https://periodicos.utfpr.edu.br/actio>. Acesso em: XXX

Correspondência:

Cileide Teixeira da Silva Polli

Rua Caraguatá, n. 52, Jardim Vila Ricardo, Londrina, Paraná, Brasil.

Direito autoral: Este artigo está licenciado sob os termos da Licença Creative Commons-Atribuição 4.0

Internacional. 